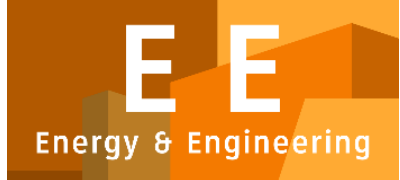

PAPER - OPEN ACCESS

\title{
Simulasi dan Eksperimental Perbedaan Kebisingan pada Transmisi Sebelum dan Setelah Perbaikan pada Tahap Transmisi 3 dan 4
}

$\begin{array}{ll}\text { Author } & : \text { Nordick Huywen } \\ \text { DOI } & : 10.32734 / \text { ee.v1i1.109 } \\ \text { ISSN } & : 2654-7031 \\ \text { E-ISSN } & : 2654-704 X\end{array}$

Volume 1 Issue 1 - 2018 TALENTA Conference Series: Energy and Engineering

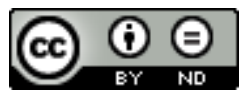

This work is licensed under a Creative Commons Attribution-NoDerivatives 4.0 International License.

Published under licence by TALENTA Publisher, Universitas Sumatera Utara
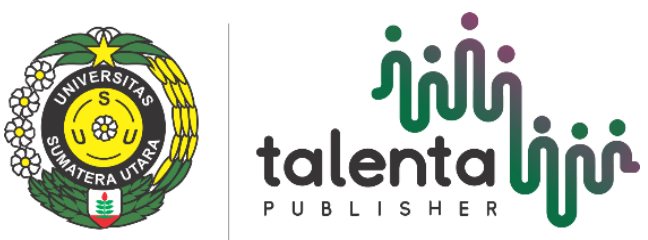


\title{
Simulasi dan Eksperimental Perbedaan Kebisingan pada Transmisi Sebelum dan Setelah Perbaikan pada Tahap Transmisi 3 dan 4
}

\author{
Nordick Huywen $^{\mathrm{a}^{*}}$, Willy ${ }^{\mathrm{a}}$ dan M. Sabri ${ }^{\mathrm{a}}$ \\ ${ }^{a}$ Fakultas Teknik, Universitas Sumatera Utara, Medan, 20155 \\ nordick_clause@yahoo.com,will_liez@yahoo.com, sabrimesin@gmail.com
}

\begin{abstract}
Abstrak
Gearbox merupakan mesin yang berfungsi untuk mentransmisikan tenaga dari motor yang berputar, kemudian disesuaikan dengan roda gigi dilanjutkan menjadi kecepatan gerak putaran bervariasi untuk dapat mengatur maju atau mundurnya mesin. Kajian ini akan menjelaskan perbedaan kebisingan transmisi tahap 3, 4 sebelum dan sesudah perbaikan. Peneliti terdahulu mendapati bahwa perbedaan ragam frekuensi dan ukuran elemen berbeda pada gearbox akan sangat mempengaruhi kebisingan. Pada kajian ini analisa dilakukan terhadap gearbox pada transmisi tahap 3 dan 4 dengan jarak tertentu yang dilingkupi nilai batas 1 lingkaran $(-\mathrm{x}, \mathrm{x}$, dan $\mathrm{z})$. Analisis akustik dilakukan pada putaran yang sama untuk melihat perbedaan kebisingan pada gearbox tersebut sedangkan pengukuran dengan sound level meter dilakukan dengan 3 arah yaitu $-\mathrm{x}$, $\mathrm{x}$, dan z. Didapati bahwa kebisingan tertinggi terjadi terhadap transmisi tahap 4 sebelum perbaikan yaitu sebesar 53,19 dB pada simulasi dan 66,1 dB pada eksperimen. Perbedaan hasil kebisingan terjadi dikarenakan pada simulasi adalah single noise dan total noise pada eksperimen.
\end{abstract}

Kata Kunci: Gearbox; BEM; Sound Pressure Level;

\section{Pendahuluan}

Pada kala ini kebisingan yang terjadi pada mobil sangat menganggu, maka dari itu sistem transmisi dilakukan penyesuaian agar dapat mengurangi kebisingan. Kebisingan dan vibrasi ditentukan oleh desain gearbox itu sendiri. Metode yang digunakan pada penelitian ini mencakup metode eksperimental dan simulasi untuk memecahkan masalah kebisingan pada transmisi / gearbox.

Jianxing Zhou, WenleiSun dan Qing Tao [1] melakukan finite element method pada gearbox dengan frekuensi yang berbeda sangat mempengaruhi hasil kebisingan yang didapatkan pada gearbox.

Mats Akerblom [2] meneliti tentang korelasi transmisi error yang akan meningkatkan kebisingan dan vibrasi. Hasil penelitian menunjukkan bahwa setelah dilakukan optimasi pada transmisi yang mengalami kesalahan atau transmission loss maka tingkat kebisingan dan vibrasi yang dihasilkan pada gearbox akan mengalami penurunan vibrasi maupun noise.

Milosav Ogjanovic [3] meneliti tentang pengaruh impak roda gigi terhadap rumah gearbox. Hasil penelitian menunjukkan bahwa setelah dilakukan simulasi pengaruh teeth impak dan ragam frekuensi gearbox akan sangat mempengaruhi kebisingan yang dihasilkan. 


\section{Metode Analitik}

Model analitik menggunakan persamaan tekanan / pressure acoustic dapat dilihat pada persamaan (1) dan (2) dibawah ini.

$$
\begin{aligned}
& L p=20 \log \frac{\text { Prg }}{\text { Pfluid }} \\
& L p=20 \log \frac{P_{\text {case }}}{P_{\text {fluid }}}
\end{aligned}
$$

Dimana:

$\operatorname{Prg}=$ tekanan suara pada roda gigi $(\mathrm{Pa})$

Pfluid = tekanan suara pada pelumas atau cairan $(\mathrm{Pa})$

Pcase $=$ tekanan suara pada housing roda gigi $(\mathrm{Pa})$

Pam = tekanan atmosfir pada sekitar roda gigi $(\mathrm{Pa})$

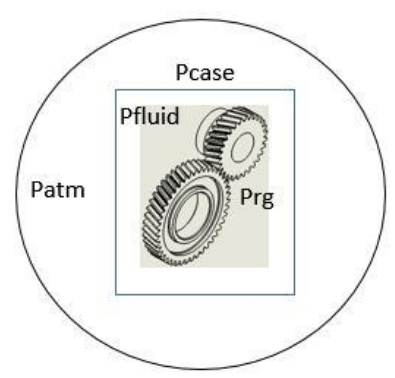

Gambar. 1. Tekanan akustik pada casing dan roda gigi

Model yang digunakan MingSian [5] yang digunakan adalah model persamaan yang menggunakan HelmholtzKirchoff yang telah dikembangkan menjadi persamaan (3) sebagai berikut:

$$
c(r) p(r)=\int_{S o}^{S n}\left[p(r o)\left(\frac{1}{R}+j k\right) \frac{e^{-j k R}}{R} \cos \theta+j w \rho v(r o) \frac{e^{-j k R}}{R}\right] d s+\int_{0}^{V 2} f(r o) G(r, r o) d V
$$

Pada gambar 2 dapat dilihat konsep akustik pada transmisi .

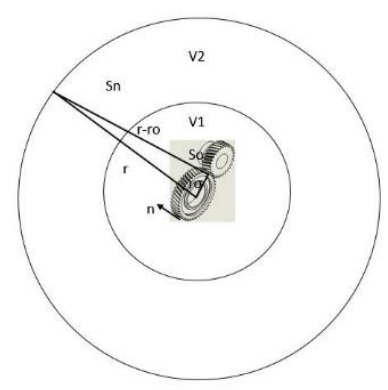

Gambar. 2. Konsep Akustik 


\section{Boundary Element Method / BEM}

Boundary element method adalah metode yang digunakan untuk memberikan batasan jarak dari ruang lingkup gearbox ke jarak tertentu yang menjadi tolak ukur pengukuran kebisingan yang ada. Boundary yang digunakan adalah 1 lingkaran, alasan dilakukan pengukuran 1 lingkaran adalah element size yang digunakan bisa dengan angka yang besar. Sebenarnya pengukuran dilakukan dengan setengah lingkaran dikarenakan batasan komputer yang ada karena beban ukuran elemen yang dilakukan pada setengah lingkaran harus kecil untuk dapat disesuaikan dengan jarak permukaan gearbox dengan ruang lingkup setengah lingkaran. Pada gambar 3 dapat dilihat nilai batas kebisingan dan meshing boundary dengan ukuran elemen $100 \mathrm{~mm}$.

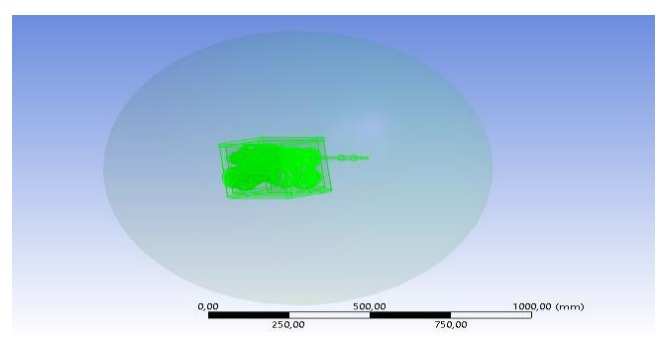

Gambar. 3. Boundary Gearbox

\section{Metode Penelitian}

Pada penelitian ini digunakan 2 metode yaitu dengan metode eksperimen dan metode simulasi. Tujuan dilakukan 2 metode ini adalah untuk dapat membandingkan hasil simulasi dan eksperimen yang didapatkan sehingga dapat disimpulkan apakah dengan metode tersebut dapat mengidentifikasi kebisingan pada transmisi.

\subsection{Eksperimental}

Penelitian dilakukan menggunakan metode setengah lingkaran $(-\mathrm{x}, \mathrm{x}, \mathrm{z})$ dengan variasi jarak sound pressure level sejauh $0,8 \mathrm{~m}$ yang meliputi persiapan alat dan bahan, set up alat, pengujian dan pengambilan data. Parameter yang diukur adalah besarnya nilai intensitas kebisingan pada tiap transmisi, pada transmisi tahap 3 dan 4.Pada penelitian ini membandingkan hasil pengujian sebelum dan setelah perbaikan untuk memperoleh perbandingan. Setelah itu maka dilakukan evaluasi hasil eksperimental dan simulasi. Berikut adalah gambar 4 dengan pengukuran dengan berbagai sumbu:
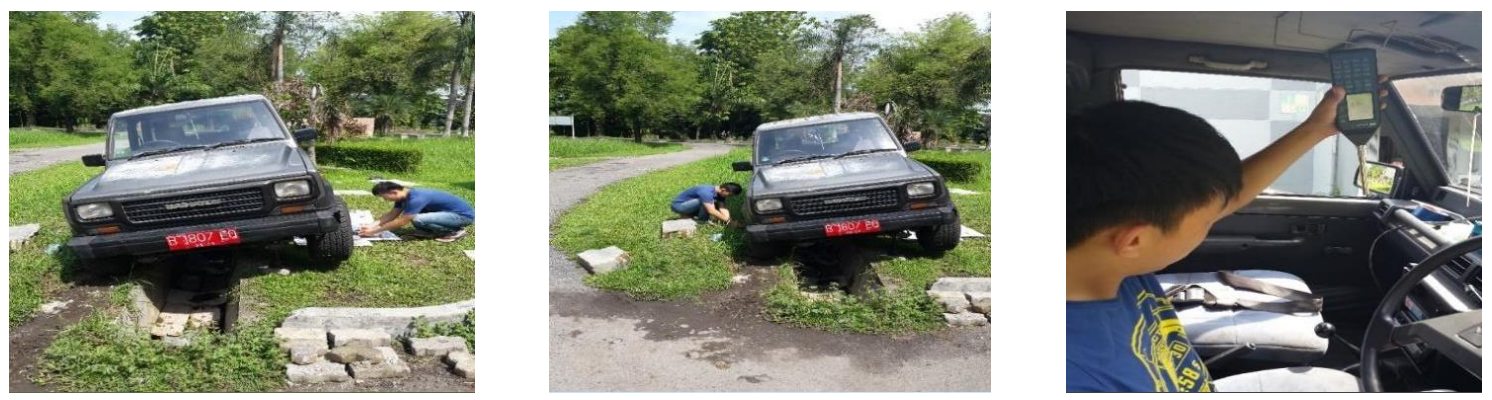

Gambar. 4. Pengukuran dengan sumbu $-\mathrm{x}, \mathrm{x}$, dan $\mathrm{y}$

\subsection{Simulasi}

Metode simulasi pada penelitian ini dimulasi dengan model CAD gearbox yang pertama - tama dilakukan pendesaian dari software dengan menggunakan sistem mate/joint pada seluruh komponen menjadi utuh kemudian dilakukan pemindahan pada software FEA akustik untuk dilakukan analisis secara lanjut. Sistem FEA akustik atau EXT acoustic digunakan untuk menghitung suara harmonik dari gearbox dengan jarak - 
jarak tertentu. Kemudian dilakukan proses mesh untuk mendapatkan satuan satuan elemen dan node pada komponen assembly. Pada gambar 5 dapat dilihat proses mesh transmisi.

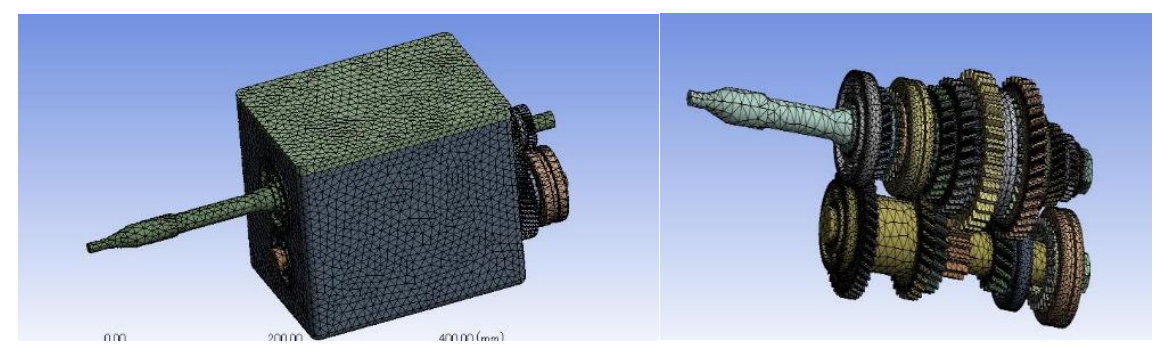

Gambar. Desain CAD mesh gearbox

\section{Hasil}

Dengan mengunakan EXT akustik harmonik pada gearbox dilakukan pengisian data data yang ada untuk menghasilkan data data perbandingan. Berikut ini adalah gambar 6 dan 7 hasil analisis akustik gigi 3 dan 4 .

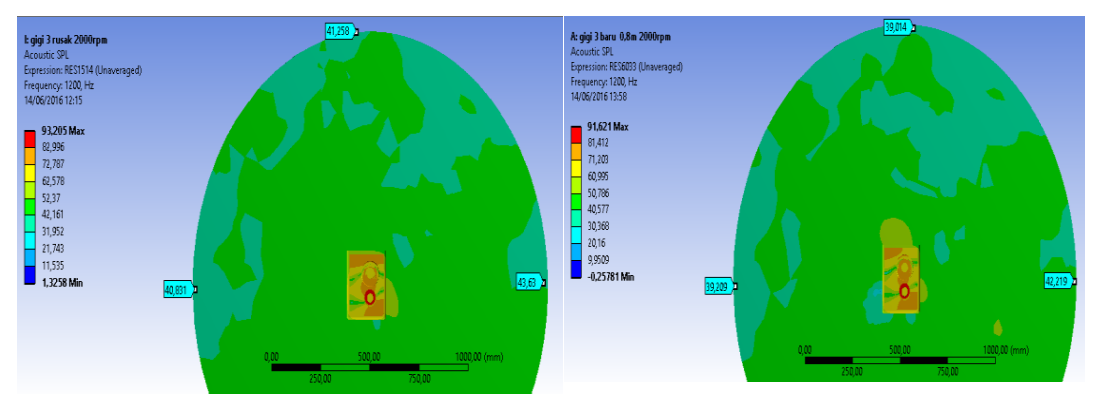

Gambar. 6. Hasil simulasi transmisi tahap 3 sebelum dan setelah perbaikan

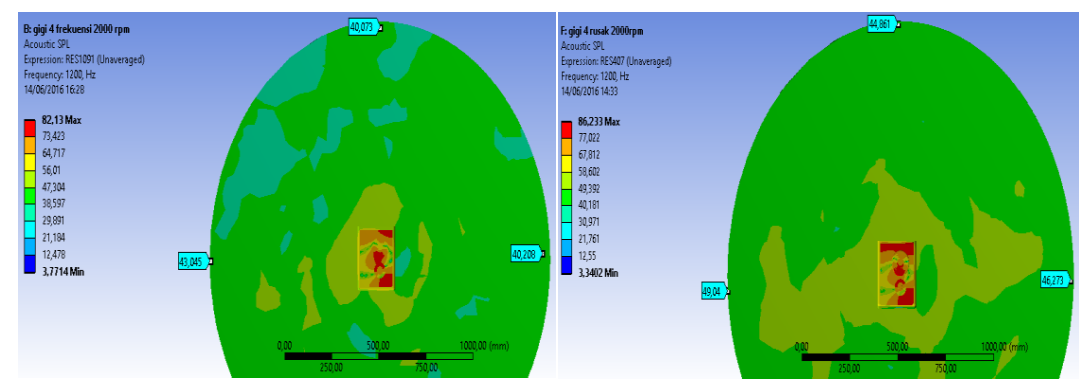

Gambar. 7. Hasil simulasi transmisi tahap 4 sebelum dan setelah perbaikan 
Tabel. 1. Tabel kebisingan sebelum dan setelah perbaikan transmisi tahap 3

\begin{tabular}{ccccccc}
\hline & \multicolumn{3}{c}{ Sebelum perbaikan transmisi } & \multicolumn{3}{c}{ Setelah perbaikan transmisi } \\
& \multicolumn{3}{c}{ tahap 3 } & \multicolumn{3}{c}{ tahap 3 } \\
\cline { 2 - 7 } Frekuensi & $-\mathrm{x}$ & $\mathrm{x}$ & $\mathrm{z}$ & $-\mathrm{x}$ & $\mathrm{x}$ & $\mathrm{z}$ \\
& $2000 \mathrm{rpm}$ & $2000 \mathrm{rpm}$ & $2000 \mathrm{rpm}$ & 2000 & 2000 & 2000 \\
& $(\mathrm{~dB})$ & $(\mathrm{dB})$ & $(\mathrm{dB})$ & $\mathrm{rpm}$ & $\mathrm{rpm}$ & $\mathrm{rpm}$ \\
& & & & $(\mathrm{dB})$ & $(\mathrm{dB})$ & $(\mathrm{dB})$ \\
\hline $1200 \mathrm{~Hz}$ & 40,83 & 43,63 & 41,25 & 39,02 & 42,21 & 39,01 \\
$1300 \mathrm{~Hz}$ & 47,51 & 49,31 & 43,65 & 49,05 & 34,19 & 42,2 \\
$1400 \mathrm{~Hz}$ & 44,2 & 44,36 & 40,07 & 42,06 & 43,61 & 38,12 \\
$1500 \mathrm{~Hz}$ & 45,03 & 45,03 & 44,07 & 42,95 & 45,05 & 43,04 \\
$1600 \mathrm{~Hz}$ & 52,3 & 38,37 & 50,26 & 46,2 & 36,15 & 48,2 \\
$1700 \mathrm{~Hz}$ & 48,14 & 52,47 & 49,14 & 45,02 & 50,21 & 50,1 \\
$\mathrm{Maks}$ & 52,3 & 52,47 & 50,26 & 49,05 & 50,21 & 50,1 \\
\hline
\end{tabular}

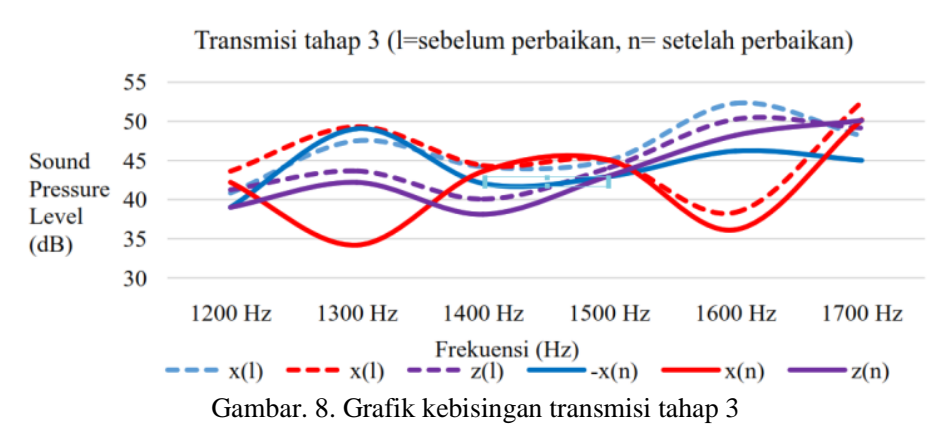

Tabel. 2. Tabel kebisingan sebelum dan setelah perbaikan transmisi tahap 3

\begin{tabular}{ccccccc}
\hline & \multicolumn{3}{c}{ Sebelum perbaikan transmisi } & \multicolumn{3}{c}{ Setelah perbaikan transmisi } \\
& \multicolumn{3}{c}{ tahap 4} \\
\cline { 2 - 7 } Frekuensi & $-\mathrm{x}$ & $\mathrm{x}$ & $\mathrm{z}$ & $\mathrm{x}$ & $\mathrm{x}$ & $\mathrm{z}$ \\
& $2000 \mathrm{rpm}$ & $2000 \mathrm{rpm}$ & $2000 \mathrm{rpm}$ & 2000 & 2000 & 2000 \\
& $(\mathrm{~dB})$ & $(\mathrm{dB})$ & $(\mathrm{dB})$ & $\mathrm{rpm}$ & $\mathrm{rpm}$ & $\mathrm{rpm}$ \\
& & & & $(\mathrm{dB})$ & $(\mathrm{dB})$ & $(\mathrm{dB})$ \\
\hline $1200 \mathrm{~Hz}$ & 49,04 & 46,27 & 44,86 & 43,04 & 40,28 & 40,07 \\
$1300 \mathrm{~Hz}$ & 45,94 & 45,84 & 46,13 & 37,31 & 38,45 & 40,01 \\
$1400 \mathrm{~Hz}$ & 45,03 & 47,12 & 43,41 & 37,09 & 42,45 & 41,8 \\
$1500 \mathrm{~Hz}$ & 43,44 & 45,52 & 48,4 & 41,02 & 42,15 & 43,06 \\
$1600 \mathrm{~Hz}$ & 53,19 & 48,73 & 46,23 & 49,04 & 45,88 & 39,01 \\
$1700 \mathrm{~Hz}$ & 50,77 & 48,3 & 52,65 & 43,16 & 39,1 & 48,41 \\
$\mathrm{Maks}$ & 53,19 & 48,73 & 52,65 & 49,04 & 45,88 & 48,41 \\
\hline
\end{tabular}




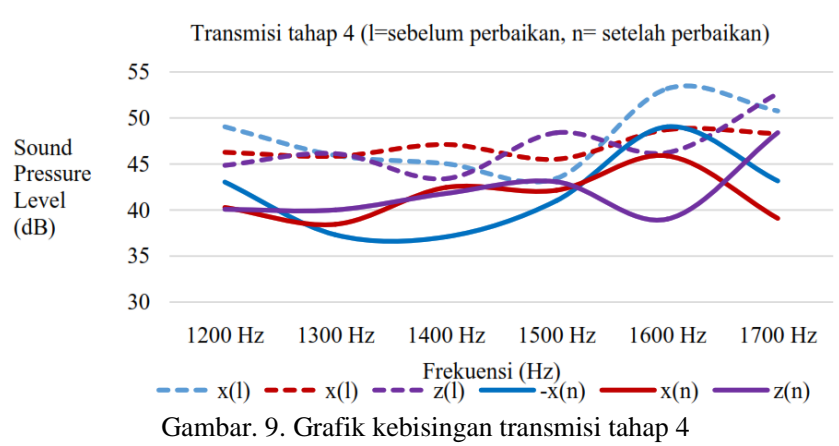

Terlihat pada gambar 8 dan 9 bahwa setelah dilakukan perbaikan akan sangat efektif mengurangi kebisingan yang terjadi pada transmisi tahap 3 dan 4 pada simulasi. Meskipun terlihat perbedaan hasil kebisingan yang terjadi dikarenakan pada simulasi adalah single noise dan total noise pada eksperimen. Pada tabel 3 dapat dilihat perbandingan data simulasi dan eksperimen dengan $(1)=$ sebelum perbaikan dan $(2)=$ setelah perbaikan.

Tabel. 3. Tabel simulasi dan eksperimen ( $\mathrm{s}=$ simulasi, $\mathrm{e}=\mathrm{eksperimen}$ )

\begin{tabular}{ccccccccc}
\hline Arah & $\begin{array}{c}\text { tahap } \\
3 \mathrm{~s}(1) \\
\mathrm{dB}\end{array}$ & $\begin{array}{c}\text { tahap 3e (1) } \\
\mathrm{dB}\end{array}$ & $\begin{array}{c}\text { tahap 3s } \\
(2) \mathrm{dB}\end{array}$ & $\begin{array}{c}\text { tahap 3e (2) } \\
\mathrm{dB}\end{array}$ & $\begin{array}{c}\text { tahap 4s } \\
(1) \mathrm{dB}\end{array}$ & $\begin{array}{c}\text { tahap 4e (1) } \\
\mathrm{dB}\end{array}$ & $\begin{array}{c}\text { tahap 4s (2) } \\
\mathrm{dB}\end{array}$ & $\begin{array}{c}\text { tahap 4e (2) } \\
\mathrm{dB}\end{array}$ \\
\hline$-\mathrm{X}$ & 52,3 & 65,42 & 49,05 & 59,12 & 53,19 & 66,1 & 49,04 & 59,12 \\
$\mathrm{X}$ & 52,47 & 61,24 & 50,21 & 59,9 & 48,73 & 63,28 & 45,88 & 59,9 \\
$\mathrm{Z}$ & 50,26 & 47,74 & 50,10 & 46,44 & 52,65 & 48,42 & 48,41 & 47,74 \\
\hline
\end{tabular}

Tabel. 4. Ralat kebisingan simulasi dan eksperimen

\begin{tabular}{|c|c|c|c|c|c|c|c|c|c|c|c|}
\hline \multicolumn{6}{|c|}{ Transmisi tahap 3} & \multicolumn{5}{|c|}{ Transmisi tahap 4} & \\
\hline \multicolumn{2}{|c|}{ sebelum perbaikan } & \multicolumn{3}{|c|}{ setelah perbaikan } & & \multicolumn{3}{|c|}{ sebelum perbaikan } & \multicolumn{2}{|c|}{ setelah perbaikan } & \\
\hline$-\mathrm{x}$ & $\mathrm{x}$ & $\mathrm{z}$ & $-\mathrm{X}$ & $\mathrm{x}$ & $\mathrm{z}$ & $-\mathrm{X}$ & $\mathrm{x}$ & $\mathrm{z}$ & $-\mathrm{x}$ & $\mathrm{X}$ & z \\
\hline $25 \%$ & $16,7 \%$ & $5 \%$ & $20,5 \%$ & $19 \%$ & $7,3 \%$ & $24 \%$ & $28 \%$ & $8 \%$ & $20 \%$ & $28,5 \%$ & $9,2 \%$ \\
\hline
\end{tabular}

Faktor - faktor yang menyebabkan persen ralat diatas pada gearbox adalah sebagai berikut :

- Eksperimen

a) Pengukuran mobil dilakukan dengan posisi diatas selokan dengan ban kanan menyentuh tanah.

b) Kebisingan lingkungan tidak stabil.

c) Suara kebisingan yang didapatkan melalui Sound Pressure Level adalah suara dari mesin,knalpot,ban,kopling dan gearbox.

- Simulasi

a) Batasan komputer tidak memungkinkan untuk melakukan simulasi secara lengkap.

b) Proses mesh pada komponen CAD gearbox kurang presisi atau dengan ukuran yang lebih kecil.

c) Parameter yang kurang lengkap. 


\section{Kesimpulan}

Berdasarkan hasil simulasi yang telah dilakukan, didapatkan bahwa kebisingan tertinggi pada transmisi tahap 3 sebelum perbaikan adalah 52,47 dB. Sedangkan pada transmisi tahap 3 setelah perbaikan kebisingan tertinggi adalah 50,21 dB. Pada transmisi tahap 4 sebelum perbaikan kebisingan tertinggi adalah 53,19 dB. Sedangkan pada transmisi tahap 4 setelah perbaikan adalah 49,04 dB. Pada eksperimen didapatkan bahwa kebisingan tertinggi pada transmisi tahap 3 sebelum perbaikan adalah 65,42 dB. Sedangkan pada transmisi tahap 3 setelah perbaikan kebisingan tertinggi adalah 59,9 dB. Pada transmisi tahap 4 sebelum perbaikan kebisingan tertinggi adalah 66,1 dB. Sedangkan pada transmisi tahap 4 setelah perbaikan adalah 59,9 dB. Pada transmisi tahap 3 sebelum perbaikan terdapat perbedaan pada simulasi dan eksperimen sebesar 12,949 dB dan setelah perbaikan adalah 9,686 dB sedangkan pada tahap transmisi tahap 4 sebelum perbaikan adalah 12,903 dan setelah perbaikan 10,854 dB. Maka dapat disimpulkan dari simulasi dan eksperimen bahwa kebisingan tertinggi terjadi pada transmisi tahap 4 sebelum perbaikan.

\section{Referensi}

[1] Jianxing Zhou, WenleiSun, and QingTao, (2014). Gearbox Low-Noise Design Method Based on Panel Acoustic Contributin, School of Mechanical Engineering, Xinjiang University, Urumqi830047, China.

[2] Mats Åkerblom, (2008).Correlation With Transmission Error and Influence of Bearing Preload.

[3] Department of Machine Design Royal institute of Technology SE-100 44 Stockholm, Sweeden. Milosav Ognjanovic, (2012). Gear Unit Housing Effect On The Noise Generation Caused By Gear

[4] Teeth Impact. University of Belgrade, Faculty of Mechanical Engineering, Serbia.

[5] Mingsian R. Bai, Jeong-Guon lh, and Jacob Benesty, (2013). Acoustic Boundary Element Method, John Wiley \& Sons Singapore Pte.Ltd, Singapore. 